\title{
EL RESCATE DE CÁNDIDO LÓPEZ: LA GUERRA DEL PARAGUAY EN EL ARTE CONTEMPORÁNEO
}

\author{
O RESGATE DE CÁNDIDO LÓPEZ: A GUERRA DO PARAGUAI NA \\ ARTE CONTEMPORÂNEA
}

\begin{abstract}
María Teresa Serralunga
Escuela Provincial de Artes Visuales "Profesor Juan Mantovani"
\end{abstract}

\section{Resumen}

Este texto analiza la manera en que la obra de Cándido López, pintor de la guerra de la Triple Alianza, o Guerra del Paraguay, es resignificada por artistas de finales del siglo XX. La investigación sobre la exposición Cándido López. Una evocación del creador de la abstracción geopolítica desde su génesis y en el contexto artístico en el que se desarrolla, revela una nueva forma de relación entre el arte y la historia argentina. El resultado de esta recuperación reivindica aquella obra como documento y como expresión artística ubicada en los márgenes de la solemnidad y el idealismo presentes en el género de la pintura histórica.

Palabras clave: Arte. Guerra. Historia. Cándido López. Benito Laren. Lux Lindner.

\section{Resumo}

Este texto analisa a maneira pela qual o trabalho de Cándido López, pintor da Guerra da Tríplice Aliança, ou Guerra do Paraguai, é ressignificado por artistas do final do século XX. A pesquisa sobre a exposição Cándido López. Uma evocação do criador da abstração geopolítica desde sua gênese e no contexto artístico em que se desenvolve revela uma nova forma de relação entre a arte e a história argentina. $O$ resultado dessa recuperação reivindica aquela obra como documento e como expressão artística situada à margem da solenidade e idealismo presentes no gênero da pintura histórica.

Palavras-chave: Arte. Guerra. História. Cándido López. Benito Laren. Lux Lindner. 


\section{Antecedente cercano: el historicismo posmoderno}

El desinterés por la innovación y la consecuente recuperación de la historia son señalados por María José Herrera (1999) como elementos propios del pensamiento de la posmodernidad.

En la arquitectura, el historicismo posmoderno se descubre en la recuperación de elementos del pasado, resultando un eclecticismo en el que la yuxtaposición de elementos de diverso origen resta unidad al conjunto. En la plástica, esa yuxtaposición se establece mediante citas de imágenes de diversas épocas de la tradición artística y en muchos casos, del pop, así como motivos del comic y de los medios masivos de comunicación.

Si bien la cita y otras variantes intertextuales tienen antecedentes muy antiguos en la historia del arte, fueron apropiadas por el posmodernismo como elemento primordial de su lenguaje. La idea de que nada es nuevo y todo ha sido ya concebido, llevó a recobrar elementos ya inventados, considerando que la creación pura no existe más que en el establecimiento de nuevas relaciones entre temas, épocas, autores o materiales.

En la Argentina de los '80, tras los primeros años de democracia, se vivió una etapa de liberalismo económico, con la apertura al capital internacional y la importación que reemplazó a la industria nacional. Se ingresó en una especie de euforia consumista, favorecida por la equiparación del peso con el dólar. Esa apertura al exterior abarcó también el campo artístico, que en Buenos Aires se identificó con el neo-conceptualismo que proponía la globalización.

\section{Los noventa}

Como alternativa opuesta, surge a fines de la década del ochenta, desde la Galería del Centro Cultural Ricardo Rojas en Buenos Aires, una tendencia que se autodefinió como marginal y se afianzó como propia del arte de los noventa. De manera comparable a la de los pop, los artistas miraron hacia la publicidad, los productos de consumo y los medios masivos de comunicación, aunque de maneras diversas. La relación de estos artistas con los productos de consumo fue menos optimista que la de los pop del 60 y más escéptica que la de sus contemporáneos norteamericanos. Ese abordaje un tanto más crítico de los productos de 


\section{EL RESCATE DE CÁNDIDO LÓPEZ: LA GUERRA DEL PARAGUAY EN EL ARTE CONTEMPORÁNEO}

consumo masivo, derivó en algunos casos en el rescate de las técnicas de factura manual y la preocupación por las artesanías tradicionales. A esa recuperación se sumó la permanencia de la mirada hacia el pasado, pero orientada más hacia adentro, esto es, hacia la propia historia personal y hacia la historia argentina, cargada ahora de diferentes matices de crítica.

\section{Al rescate del artista}

Cándido López era considerado un documentalista de la guerra del Paraguay, de la cual participó como soldado del Batallón argentino de San Nicolás. Sus cuadros de la guerra pueden apreciarse desde dos miradas diferentes: una, como paisaje poblado de personas que se mueven; otra, como suma de pequeñas escenas, que muestran los detalles, las vivencias y las circunstancias de la vida y la muerte en la guerra como acontecimientos individuales. Se había alistado sin ninguna experiencia militar, habiendo renunciado a la posibilidad de viajar a Europa, tal como lo hacían los pintores argentinos de la época. Como pintor, había estudiado en los talleres de Cayetano Descalzi, Baltasar Verazzi e Ignacio Manzoni, y había vivido de la pintura de retratos pintados y daguerrotipos.

Partió a la guerra cargando sus lápices y papeles, con la intención de documentar los hechos. Para eso, entre una y otra batalla, el Teniente segundo López apuntó con fidelidad datos del paisaje, escenas de la vida en el campamento y desembarcos. Tomó nota de las fechas y los acontecimientos, lo que más tarde le serviría para desplegar en sus cuadros todos los datos posibles y armar una cronología de la guerra: el paso del río Corrientes; el embarque en Paso de los Libres; el campamento de Uruguayana; la escuadra en Paso de la Patria; las batallas de Yatay, Estero Bellaco, Tuyutí y Boquerón. Su participación en la guerra terminó en la derrota de los aliados en Curupaytí. Retirado de la guerra por la amputación de su mano derecha, Cándido López se dedicó a lo que sería su meta: la documentación completa de la guerra de la Triple Alianza para perpetuar los hechos en la memoria de los argentinos. En sus pequeños cuadros describió la flora del lugar, el río, las islas, las barrancas, la playa, la selva y los grandes cielos. Su fidelidad hacia la representación y descripción escrita del paisaje, permitiría a José Luis García revelar cada uno de los escenarios en el largometraje documental "Cándido López, los campos de batalla" (2005), aunque algunos ya modificados por el hombre o los cambios de la selva y el río. 


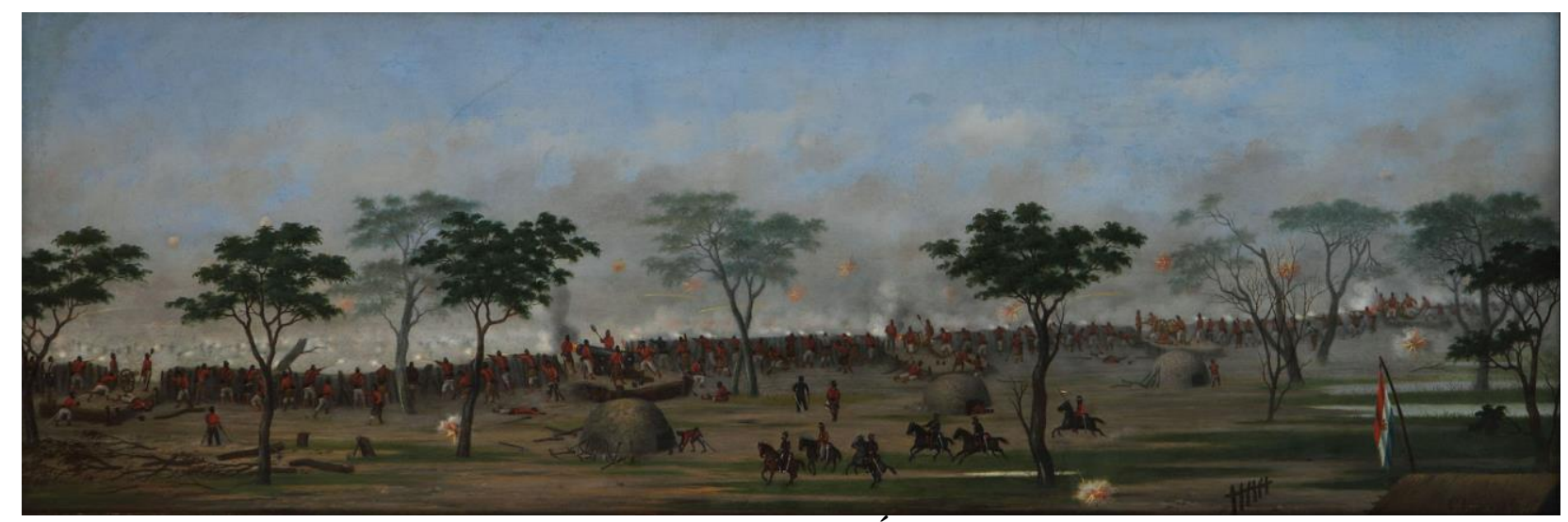

Fotografía I: Cándido López Trinchera de Curupaytí, 1899. Óleo sobre lienzo. Museo Nacional de Bellas Artes.

Fuente: Google Art Project (iQFskrK0ykULXw).jpg - dominio público

Su intención documentalista, para la cual no necesitaba demostrar las armónicas proporciones ni los claroscuros academicistas aprendidos, influyó seguramente en la percepción de la crítica. Fue apreciado como artista recién en 1936, cuando José León Pagano lo incluyó en "El arte de los argentinos" y escribió una monografía sobre su obra, gran parte de la cual se exhibía en el Museo Histórico Nacional de Buenos Aires. Un poco más tarde, Julio Payró lo comparó con los miniaturistas del siglo XV.

En 1968, cinco años después del ofrecimiento por parte de los familiares del pintor, el Museo Nacional de Bellas Artes aceptó la donación de un conjunto de sus cuadros de batalla y un autorretrato. Tres años más transcurrieron para que esa obra se expusiera en el museo, hecho que modificó notoriamente su valoración estética.

A finales del siglo XX Rafael Cippolini reconoció tres etapas en la apreciación de Cándido López: la primera como creador de un documento de época, la siguiente como pintor de singular oficio y la última como "autor conceptual y explorador de universos" (CIPPOLINI, 2003). En esta tercera etapa se encuentra la estimación que de él hicieron Lux Linder y Benito Laren, en una muestra exhibida desde el 28 de agosto hasta el 16 de septiembre de 2000 en la galería del Centro Cultural Ricardo Rojas.

\section{Reflexiones sobre la invención}

Lindner (2000) explicó en un artículo la génesis de la muestra: originariamente proyectada por tres artistas, el tercero, Londaibere, quedaría finalmente encargado de la 


\section{EL RESCATE DE CÁNDIDO LÓPEZ: LA GUERRA DEL PARAGUAY EN EL ARTE CONTEMPORÁNEO}

curaduría, si bien la idea había surgido de algunos de sus cuadros. Estos incluían latas aplastadas y pequeñas formas oscuras, sugiriendo la idea de pantanos o juncales bajo un cielo extrañamente iluminado. A ese elemento se sumó el carácter espiritual y esotérico, aportado por los intereses personales de Benito Laren y también de Lux Lindner. Éste, fanático de la historieta, relacionó la imagen de bañados con las ilustraciones de Juan Arancio en escenas de la Mesopotamia. La idea se transformó y apareció Cándido López cuando Laren volvió de Paraguay, a donde, según la explicación de Lindner, había viajado para buscar los tesoros escondidos por los paraguayos, encontrando objetos menos valiosos pero que también tenían que ver con las huellas de la Guerra de la Triple Alianza. Además, la coincidencia geográfica en San Nicolás -ciudad natal de Laren- viró su atención hacia las obras del pintor exhibidas en la Casa del Acuerdo de San Nicolás, otra de las razones por la cual la idea de Juan Arancio fue desplazada por la de Cándido López.

\section{El contexto de exposición}

La Galería del Centro Cultural Ricardo Rojas - Centro de Extensión de la Universidad de Buenos Aires - inaugurada en agosto de 1988, fue desde sus inicios un espacio de consagración de jóvenes artistas emergentes. Su curador hasta 1997 fue el artista Jorge Gumier Maier, quien promovió desde un "modelo curatorial doméstico" una idea de arte opuesto a la intelectualización del neo-conceptualismo vigente y autónomo de todo compromiso político.

La manera en que esta institución convocaba a los artistas noveles, fue referida por el mismo Laren, quien contó su propia experiencia. En 1991 vio un aviso en el diario Clarín en el que el Rojas buscaba artistas.

Como yo trabajaba siete días seguidos, y después tenía cuatro libres, me vengo a Capital a ver qué podía hacer. Me fui con todo el material y me recibieron Pablo Bolaño, Gumier Meier, Magdalena Jitrik y otra chica. Les gustó y enseguida me dieron fecha (CALMET, 2002, p.45).

A esta forma de convocatoria se sumó otro elemento que resultaría legitimador: Ramona, la revista que se especializó en el arte de la década del 90 presentando a los artistas que, por su carácter de emergentes, no figuraban en otras publicaciones. Su editor fundador, Gustavo Bruzzone, fue construyendo una colección de arte de la década desde el surgimiento 
mismo de los artistas, cuando todavía su nivel de legitimación era insuficiente para elevar el precio de las obras.

El paradigma promovido por el Rojas fue descrito por Inés Katzenstein como "el artista como freak, aislado en la singularidad de su mundo personal, produciendo pacientemente y aparentemente sin pretensiones un objeto que se iba a valorar por su rareza, su ingenuidad, y su preciosismo kitsch" (KATZENSTEIN, 2003, p.9).

En 2006, fue ampliado el reducido espacio en el que se había iniciado la galería. Tres años después, una muestra por el vigésimo aniversario intentó borrar la imagen ya mitificada de la galería como espacio conformador de un modelo de arte argentino de los 90, el que fuera considerado por su ausencia de compromiso político, sus preferencias cromáticas y su imaginario popular, como arte light, arte rosa o arte guarango.

Frente a esas representaciones del arte de la década, Carlos Basualdo (1994) afirmaba que la producción del Rojas tenía una posición cadavérica, que se apropiaba de los discursos del arte internacional para volverlo críticamente en contra de sí mismo, realizando una doble crítica. Por un lado, lo hacía ironizando sobre el discurso del arte internacional y por otro, tácitamente, sobre la propia historia del arte argentino y las condiciones actuales de producción.

\section{La abstracción geopolítica}

El título de la muestra, "Cándido López. Una evocación del creador de la abstracción geopolítica", contiene dos ideas. Por un lado, la de evocación, que nos presenta un recuerdo, un homenaje. Sugiere una intención de los artistas de reivindicar a Cándido López como artista original.

Por otro, el concepto de abstracción geopolítica. Una de las concepciones la define como una construcción, una representación, de la cual suelen valerse los países poderosos para someter "legítimamente" a los más débiles. Atendiendo a las palabras de Lindner en una entrevista, existe vinculación entre esa postura y su pensamiento:

Solano López podrá haber sido un tirano, pero el hecho es que el país tenía su industria. En definitiva, los países latinoamericanos hicieron el trabajo sucio para que las mercancías pudieran circular como deseaba el 


\section{EL RESCATE DE CÁNDIDO LÓPEZ: LA GUERRA DEL PARAGUAY EN EL ARTE CONTEMPORÁNEO}

imperialismo de entonces. Fue como la Guerra del Golfo, sólo que ahí la intervención de Estados Unidos estuvo mucho más clara (RIAL UNGARO, 2000, p.12).

Este posicionamiento lo desplazaría, al menos considerando sus palabras, de la omisión política de la que se ha acusado a los artistas de la década.

Además, el concepto de abstracción geopolítica, trasladado al campo artístico, podría ser aplicado a la marginalidad de Cándido López en el contexto artístico del siglo XIX, equiparable, en la distancia, a la marginalidad, en este caso deliberada, de los artistas argentinos del '90 con respecto al contexto mundial.

Considerando el sentido del humor en otros escritos de Lindner, cargados de absurdos y juegos de palabras, es posible también que su concepto tenga que ver con la descripción de un espacio, un paisaje, un contexto físico en el que Cándido López pone en juego una especie de abstracción pictórica en la que no jerarquiza ningún punto del cuadro, lo que se relaciona con la comparación que se hiciera de su pintura con el all over de Jackson Polock.

Las tres suposiciones sobre la "abstracción geopolítica" podrían tomarse como válidas, ya que de ninguna manera se contraponen.

\section{La muestra}

En la muestra, las obras de Cándido López se reconocen en los títulos o partes de ellos, en la composición y en el formato horizontal, si bien las obras son de la mitad de tamaño que aquéllas. En las escenas, que mantienen la individualidad de cada artista, se recrean las batallas y otros sucesos de la guerra con imágenes de mundos irreales o de ciencia ficción, y de una especie de imaginario actual salido de la mezcla televisiva de ficción y realidad. El humor y el absurdo se presentan en escenas en las que los protagonistas son caballos de cotillón, estatuillas del premio Oscar (Laren) y absurdas máquinas industriales (Lindner).

Luis Lindner apela al lenguaje de la historieta -coherente con su apasionamiento por el género- en líneas de aparente improvisación que resultan definitivas mediante las técnicas de grabado como la emulsión sobre metal. Respondiendo a sus conocimientos de ingeniería título universitario que ostenta- aparecen en su obra proyectos irracionales que recuerdan las máquinas inútiles de Jean Tinguely y los apéndices mecánicos de Xul Solar -de quien 
probablemente tomó el seudónimo Lux para reemplazar su nombre de pila (Luis) y con quien ambos artistas de la muestra comparten intereses esotéricos e imaginarios futuristas.

Laren es quien más se apropia de las imágenes de consumo masivo, en una parodia que combina, en un mismo espacio, estereotipos representativos de diferentes épocas de la historia.

Utiliza las técnicas artesanales como la pintura sobre vidrio, empleando también materiales propios de las llamadas "manualidades", como brillantina, papeles metalizados y mostacillas, siendo esto para Gustavo Bruzzone "...la exacerbación de la imagen 90 en el remolino de un aparente sinsentido" (BRUZZONE, 2001, p.6).

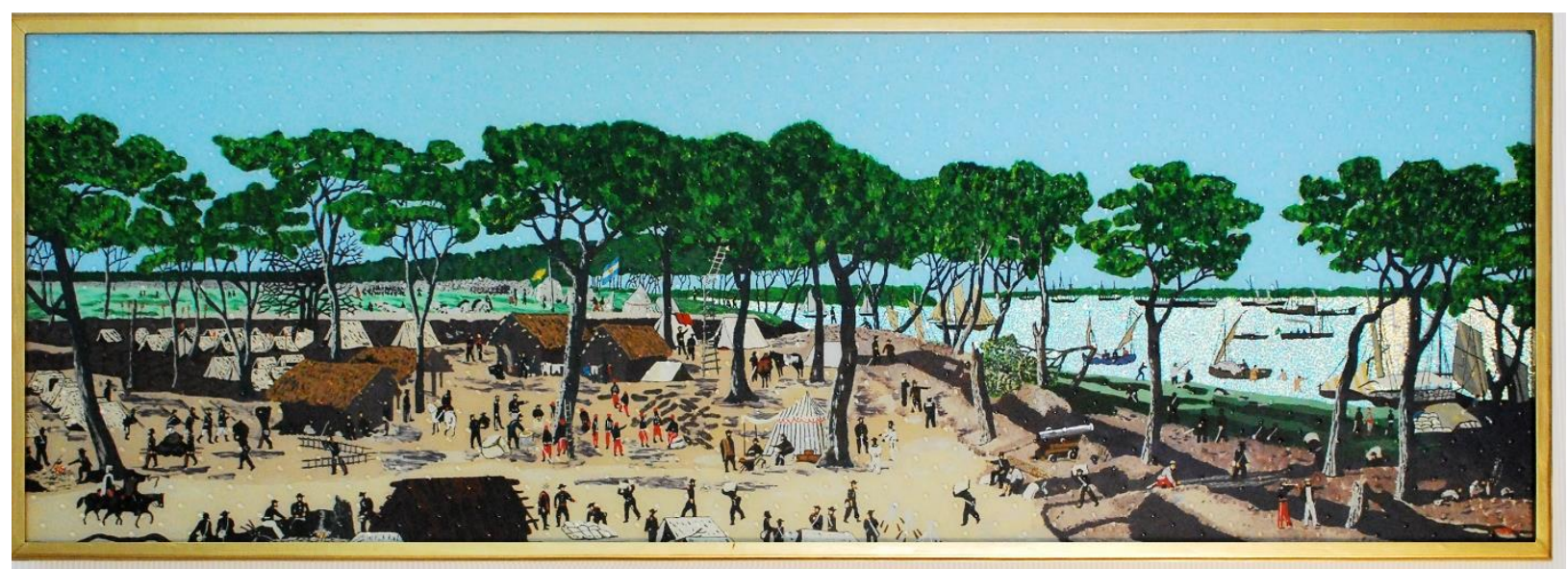

Fotografía II: Obra de Benito Laren. Pintura sobre vidrio. Fotografía gentileza de Benito Laren. Basada en la pintura de Cándido López "Vista interior de Curuzú mirado de aguas arriba (norte a sur) el 20 de septiembre de 1866" (1891), óleo sobre lienzo, que se encuentra en el Museo Nacional de Bellas Artes, Buenos Aires.

El uso de estos materiales innobles y de tradición "escolar", se relaciona con el brillo aparente de shows televisivos, del que forma parte un elenco de modelos y coreógrafas presentes en su obra; un simulacro de los brillos artificiales que constituye una forma de desacralización estética que acerca el arte a la vida cotidiana. Había comenzado la pintura sobre vidrio en 1987, cuando conoció a alguien que realizaba un procedimiento de pintura sobre espejos. Se le ocurrió agregarle un vidrio, para lograr más brillo, decidiendo entonces registrar el sistema, que resultaba una especie de vitraux con un espejo. Más adelante incorporó la brillantina y luego los papeles y logró crear distorsiones visuales con vidrio de 


\section{EL RESCATE DE CÁNDIDO LÓPEZ: LA GUERRA DEL PARAGUAY EN EL ARTE CONTEMPORÁNEO}

reloj espejado. La obsesión por los brillos y los reflejos, propia del kitsch, lo llevó a crear cuadros físicos con luces artificiales.

En una de las obras de la muestra, Velatorio del primer soldado muerto, Laren evoca los tesoros escondidos por los paraguayos para salvarlos del saqueo de los soldados de la alianza, contraponiéndoles estatuillas doradas de los premios Oscar, verdaderos tesoros del siglo XX. Con éstas conforma un batallón que está velando al soldado Oscar -el nombre aparece escrito con los colores patrios- haciendo referencia al primer muerto del Batallón de San Nicolás representado por Cándido López.

Aparecen citas de otros momentos de la historia de los dos siglos, como la que relaciona la imagen fantasmagórica del antebrazo cortado de Cándido López con el gauchito que fue mascota del Mundial del 78, ya resemantizado debido a que ese evento deportivo se percibió posteriormente como símbolo de dictadura.

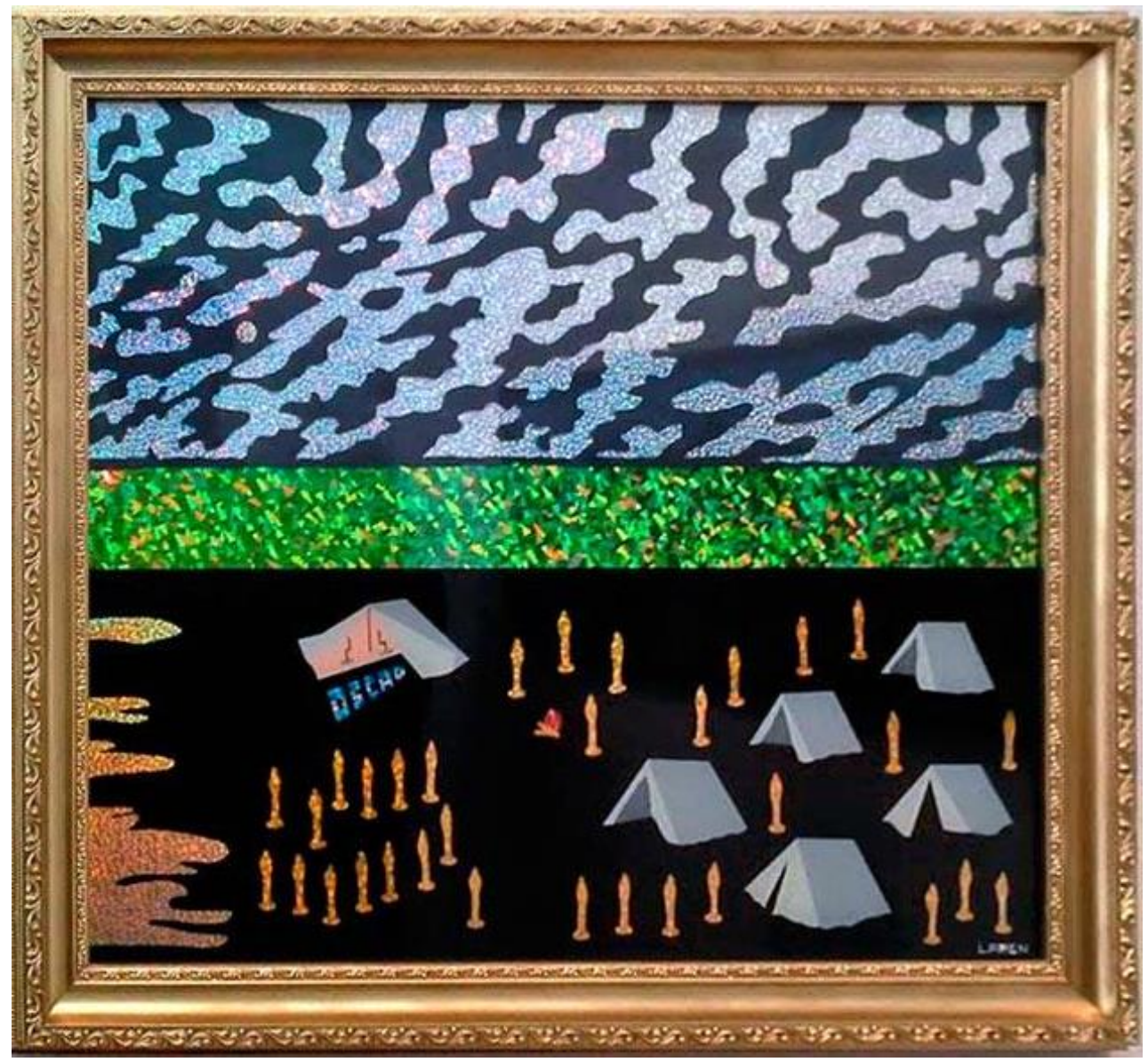

Fotografía III: Obra de Benito Laren "Velatorio del primer soldado muerto", pintura sobre vidrio. Fotografía gentileza de Benito Laren.

Basada en la pintura de Cándido López "Velatorio del primer soldado muerto, perteneciente al Batallón de Guardias Nacionales San Nicolás" (1887/1902), óleo sobre lienzo.

\begin{tabular}{l|l} 
Revista RBBA & Revista Binacional Brasil Argentina
\end{tabular} 


\section{Conclusión: La historia como material}

"La historia argentina es mucho más fantástica que nuestras obras..." (RIAL UNGARO, 2000, p.13), afirma Lindner, quien en muchas ocasiones ha tomado la historia como materia prima. Según Marcela Calcagno, "... para Lindner política e historia son plastilina ... una Plaza Sésamo de sensaciones que parece no tener fin" (CALCAGNO, 2001, p.40).

En la exposición de Lindner y Laren existe una reivindicación del pintor que, habiendo peleado en el bando vencedor, describió la guerra de una manera particular. En sus cuadros no hay jerarquía de personajes y escenas, no hay diferencia entre buenos y malos, nativos y extranjeros, vencedores y vencidos.

Lindner toma la historia de la guerra del Paraguay con una actitud revisionista que, a la distancia, considera como sus causas al capitalismo y la política del libre comercio alentados por el imperio británico, más allá de las aparentes cuestiones limítrofes que se alegaron en su tiempo. Así lo explicó en una entrevista en la que, además, afirmó que los cuadros de Cándido López muestran "los movimientos de partículas latinoamericanoides en los estanques de saliva cáustica del primer capitalismo" (RIAL UNGARO, 2000, p.13). La revisión de la historia argentina, en este caso, pone a la figura de Mitre como instrumento de ocultos intereses mayores, pero no ubica a la pintura de López como discurso que exalte a los próceres victoriosos.

Hay en esta exposición una indirecta revisión de la historia y también de la historia del arte, señales de la producción cadavérica a la que se refería Basualdo. La descontextualización de los elementos que se presentan, en tonos de imágenes fantásticas o de sátira, el reducido tamaño de las obras, la utilización del lenguaje de historieta y los procedimientos con materiales cercanos al kitsch, desacralizan el tema de las pinturas de Cándido López. Pero la intención de la muestra no parece ser el desaire al pintor -a quien, por el contrario, se reivindica- sino la ridiculización de la guerra misma, más precisamente la de la pintura de guerra como género legitimador de los vencedores. 


\section{EL RESCATE DE CÁNDIDO LÓPEZ: LA GUERRA DEL PARAGUAY EN EL ARTE CONTEMPORÁNEO}

\section{Referencias}

ALONSO, R. Crónicas en Technicolor. Pop, euforia y nostalgia en el arte argentino en Catálogo de Inoxidable Neopop, Santiago de Chile, 2006. Disponible en http://www.roalonso.net/es/arte_cont/pop_argentino.php Acceso 2/2/2018

BASUALDO, C. Arte contemporáneo en Argentina, entre la mímesis y el cadáver en Art from Argentina 1920-1994, Oxford, The museum of modern art, Oxford, 1994

BERTONE, C. Batallas contemporáneas. Revista Ramona No 5, Buenos Aires, septiembre de 2000. Disponible en http://70.32.114.117/gsdl/collect/revista/index/assoc/HASH0152.dir/r05_07nota.pdf Acceso: $15 / 1 / 2018$

BRUZZONE, G. Los '90: el libro, la imagen. Revista Ramona $N^{\circ} 11$, Buenos Aires, abril/mayo de 2001. Disponible en http://70.32.114.117/gsdl/collect/revista/index/assoc/HASH33f0.dir/r11_04nota.pdf Acceso $2 / 2 / 2018$

CALCAGNO, M. Rivadavias iluminados. Revista Ramona $N^{\circ} 11$, Buenos Aires, abril/mayo de 2001. Disponible en: http://70.32.114.117/gsdl/collect/revista/index/assoc/HASH01d8.dir/r11_37nota.pdf Acceso 5/2/2018.

CALMET, I. Yo ya extrañaba la fama de chiquito. Revista Ramona 21-22, Buenos Aires, 27/06/2002. Disponible en http://70.32.114.117/gsdl/collect/revista/index/assoc/HASH01c3/5e8599a6.dir/r2122_21nota.pdf

Acceso 2/2/2018.

CASANOVAS, L. Historia del arte en el Rojas. Diario La Nación, Buenos Aires, 4-10-2009.

CIPPOLINI, R. Escenas de la vida militar. Revista Ñ, Clarín, Buenos Aires, 26.4.2003 http://edant.clarin.com/suplementos/cultura/2003/04/26/u-00701.htm Acceso: 2/2/2018.

Coleccionismo ATP, Diario La Nación, Buenos Aires, 9-8-2008. http://www.lanacion.com.ar/nota.asp?nota_id=1036762 Acceso: 2/12/2017

GARCíA J. Cándido López. Los campos de batalla. Película documental. Argentina, Paraguay, 2005.

HERRERA, M. J. Los años setenta y ochenta en el arte argentino, entre la utopía, el silencio y la reconstrucción, en BURUCÚA J.E. Arte, sociedad y política Vol. 2. Buenos Aires, Ed. Sudamericana, 1999.

KATZENSTEIN, I. Acá lejos. Arte en Buenos Aires durante los 90. Revista Ramona $\mathrm{N}^{\circ} 37$, Buenos Aires, diciembre de 2003. Disponible en 
http://70.32.114.117/gsdl/collect/revista/index/assoc/HASH01df/bfac6d98.dir/r37_02indice.p df Acceso: 2/2/2028

LINDNER, L. Cándido López como abstracto geopolítico. Revista Ramona No 5 , Buenos Aires, septiembre de 2000.2 Disponible en: http://70.32.114.117/gsdl/collect/revista/index/assoc/HASH462a.dir/r05_10nota.pdf Acceso: $5 / 2 / 2018$

LUNA, F. y otros. Cándido López en TORRES M (Coordinación) Pintura argentina 2. Buenos Aires, Ediciones Banco Velox, 2001.

PRIOR, A, Cándido López o la pintura histórica como inscripción siniestra. Revista Ramona $\mathrm{N}^{\circ}$ 5. Buenos Aires, septiembre de 2000. Disponible en: http://70.32.114.117/gsdl/collect/revista/index/assoc/HASH0152.dir/r05_07nota.pdf Acceso: 2/2/2018.

RIAL UNGARO, S. ¿Cándido yo? Revista Radar, Buenos Aires, 3-9-2000. Año 5 N²12. P. 12-13.

USUBIAGA, V. Pintura Subyacente. Meditaciones, evocaciones y variaciones sobre lo pictórico en el arte contemporáneo, Catálogo de la muestra "Pintura Subyacente", Centro Cultural de España en Buenos Aires, 2006.

\section{Sobre a Autora}

María Teresa Serralunga. Licenciada en Artes Visuales (UNL) Profesora Superior de Artes Visuales especializada en Escultura, Postitulada en Arte americano y argentino (Escuela Provincial de Artes Visuales "Profesor Juan Mantovani" de Santa Fe). Docente ISPI No 9105 "Dra. Sara Faisal”. Docente y Directora de la EPAV N³023 "Profesor Juan Mantovani". Santa Fe, Argentina. Correo Electrónico: mariateresaserralunga@hotmail.com 